\title{
ANALISIS LENDUTAN MODEL SISTEM CAKAR AYAM MODIFIKASI DENGAN PEMBEBANAN TUNGGAL (BEBAN TITIK)
}

\author{
Lutfi Ahmad Yudandi ${ }^{1}$, Bambang Setiawan ${ }^{1}$ dan Noegroho Djarwanti ${ }^{1}$ \\ ${ }^{1}$ Civil Engineering Department, Sebelas Maret University, Jl. Ir. Sutami 36 A Surakarta \\ Email: lutfiyudandi@gmail.com
}

\begin{abstract}
Soft soil has low bearing capacity and high compressibility that can cause instability and longterm degradation that can make around some road settlement or wavy. A solution to prevent this soft soil problem was built Modified Chicken Foot, The function of Chicken Foot Foundation is to increase its bearing capacity. This research is using single load with variation distance of triangle foot foundation pattern whereas analysis of deflection using finite element method based. The research shows displacement result is depend on distance between load position and foot foundation, the closer distance between foot foundation the less it would result. The displacement result that happened at roadside is larger than at middle of the road, the difference between them is -6,8\% up to 67\% and The displacement result that happened in plate without pipe is larger than a plate with pipe, the difference between them is $12,31 \%$ up to $59,41 \%$
\end{abstract}

Keywords: Displacement, CAM, FEM, single load

\begin{abstract}
ABSTRAK
Tanah Lunak mempunyai kuat geser yang rendah dan kompresibilitas yang dapat menyebabkan beberapa jalan di sekitar tanah tersebut rusak atau bergelombang. Upaya untuk mengatasi permasalahan ini salah satunya dengan Sistem Cakar Ayam Modifikasi (CAM), sistem ini dapat berfungsi untuk menambah daya dukung tanah. Penelitian ini menggunakan beban tunggal dengan variasi posisi pada perkerasan dengan pola penempatan cakarnya segi tiga, sedangkan analisa lendutan menggunakan software berbasis Metode Elemen Hingga. Hasil penelitian menunjukkan bahwa lendutan bergantung dari jarak antara posisi beban dengan cakar, semakin kecil jarak antar cakar semakin kecil lendutan. Besarnya lendutan berada di pinggir pelat juga lebih besar dibanding di tengah pelat, selisih perbandingannya yaitu sebesar $-6,8 \%$ hingga $67 \%$ dan pada perkerasan tanpa CAM lebih besar di banding dengan CAM selisih perbandingannya $12,31 \%$ hingga $59,41 \%$ pada berbagai posisi beban dan jarak antar cakar.
\end{abstract}

Kata kunci: CAM, MEH, lendutan, beban titik

\section{PENDAHULUAN}

Sistem Cakar Ayam telah terbukti menambah daya dukung bangunan di atas tanah lunak yang digunakan untuk fondasi bangunan gedung, runway dan tower ditemukan oleh Sediyatmo pada tahun 1961. Namun permasalahanya bila beban timbunan yang relatif berat, seluruh sistem akan mengalami penurunan yang berlebihan. Salah satu usulan solusi permasalahan ini, pada cakar beton seberat 1 ton diubah menjadi galvanis anti karat seberat $35 \mathrm{~kg}$ sehingga menjadi lebih ringan dan terdapat koperan pada pinggir perkerasan untuk mengurangi air yang masuk ke dalam subgrde, sistem ini kemudian disebut Cakar Ayam Modifikasi (CAM). Salah satu metode yang mampu membantu perancangan sistem Cakar Ayam Modifikasi ini adalah Metode Elemen Hingga (MEH) yang telah teruji memberikan hasil analisis yang akurat diantaranya adalah untuk perancangan. Model elemen hingga yang dikembangkan mencangkup kombinasi dari elemen-elemen pelat lentur (plate bending) untuk memodelkan slab, elemen - elemen cangkang 3D (shell) untuk memodelkan cakar dan elemen pegas (spring) untuk memperhitungkan pegaruh gaya-gaya yang terjadi pada subgrde

Penelitian ini bertujuan untuk mengetahui lendutan akibat beban tunggal pada berbagai posisi dan pengaruh pola segitiga dan variasi jarak antar cakar pada sistem CAM dan tanpa CAM. Penelitian ini menggunakan data sekunder yang diambil dari penelitian yang telah dilakukan oleh Setiawan (2015), dengan dimensi pelat $27 \mathrm{~m} \mathrm{x}$ $7,25 \mathrm{~m}$. Analisis pada penelitian ini menggunakan software berbasis Metode Elemen Hingga yang sebelumnya juga telah diteliti oleh Nawangalam (2008) menganalisis Sistem Cakar Ayam dengan menggunakan metode elemen hingga (SAP 2000) secara 3 D terhadap hasil uji model skala penuh di Waru Surabaya dan Bandara Polonia Medan. Hasil penelitiannya menunjukkan bahwa untuk beban-beban rendah 20 ton (200 kN), pemodelan elemen hingga secara linier sudah cukup memuaskan, sedangkan untuk beban tinggi seperti beban roda pesawat, makadiperlukan analisis non linier. Romadhoni (2008) melakukan pemodelan Sistem Cakar Ayam secara 3D penuh mencakup elemen pelat beton dan pipa cakar sebagai elemen shell 3D, hasil pemodelan 
ini menyimpulkan bahwa pembebanan paling kritis Sistem Cakar Ayam adalah bila beban terletak di tepi dan pojok, karena menghasilkan lendutan dan momen yang besar. Penelitian ini diharapkan dapat mengetahui perilaku lendutan dengan pembebanan tunggal pada sistem CAM yang terletak di tanah lunak.

\section{DASAR TEORI}

\section{Beban}

Pembebanan tunggal berdasarkan Westegaard Solution yang menganalisis tegangan dan pola lendutan pada tiga titik pembebanan utama yaitu pembebanan tepi (edge loading), pembebanan pada pusat (interior loading) dan pembebanan pada ujung (corner loading) Gambar 1. Besarnya beban titik berdasarkan Muatan Sumbu Terberat yang disaratkan oleh Balai Geoteknik Jalan, Departemen Pekerjaan Umum Republik Indonesia, untuk perancangan perkerasan kaku adalah sebesar 10 ton $(100 \mathrm{kN})$, namun masih diberikan toleransi sebesar 90\% sehingga menjadi 19 ton $(190 \mathrm{kN})$.

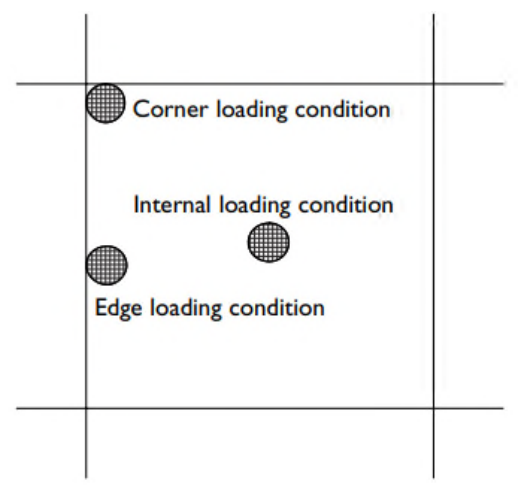

Gambar 1. Pola pembebanan pada plat menurut Westegaard Solution (Abass,A 2002)

\section{Sistem CAM}

Sistem CAM mengandalkan tekanan lateral di sekitar cakar yang dipengaruhi oleh modulus reaksi subgrade untuk melawan rotasi dengan membentuk momen perlawanan, semakin besar nilai modulus reaksi subgrade semakin besar perlawanan momen yang dihasilkan. Hardiyatmo (2014) menjelaskan bahwa sistem Cakar Ayam cocok digunakan pada tanah yang bermasalah atau tidak stabil. Cakar berfungsi sebagai pengaku yang akan menjaga agar pelat beton dan material dibawahnya tetap dalam kontak.

\section{Metode Elemen Hingga}

Metode elemen hingga adalah cara pendekatan analisis struktur secara numeric dimana struktur kontinum dengan derajat kebebasan tak hingga disederhanakan dengan disktretasi kontinum dalam elemen-elemen kecil yang umumnya memiliki geometri lebih sederhana dengan derajat kebebasan tertentu (berhingga), sehingga lebih mudah dianalisis. Beberapa elemen yang dianalisis yaitu Elemen Shell, Elemen Spring dan Elemen Solid. Penelitian ini menggunakan program SAP2000 v. 20

\section{METODE PENELITIAN}

\section{Tanah lunak}

Data sekunder yang digunakan meliputi modulus reaksi subgrade yang diambil dalam Setiawan (2015) mengambil sampel tanah di Desa Widodaren, Kecamatan Banjarjo, Kabupaten Ngawi, Jawa Timur. Data yang di gunakan pada pemodelan berasal dari hasil Plate Load Test yang kemudian di dapatkan nilai modulus reaksi subgrade vertikal $\left(k_{v}\right)$, horisonal $\left(k_{h}\right)$ dan gesek $\left(k_{\tau}\right)$. Digunakan nilai koefisien reaksi subgrade horizontal $\left(k_{h}\right)$ sebesar $10 \times k_{v}$. Modulus subgrade vertikal tanah $\left(k_{v}\right)$ sebesar 13.196,14 $\mathrm{kN} / \mathrm{m} 3$, modulus subgrade horizontal tanah $\left(k_{h}\right)$ sebesar 131.961,4 kN/m3, modulus subgrade horizontal tanah $\left(k_{\tau}\right)$ sebesar 5.078,74 kN/m3.

\section{Beban}

Beban yang digunakan adalah beban tunggal yang mengacu pada besarnya berdasarkan Muatan Sumbu Terberat yang disaratkan oleh Balai Geoteknik Jalan, Departemen Pekerjaan Umum Republik Indonesia untuk perancangan perkerasan kaku adalah sebesar 10 ton $(100 \mathrm{kN})$. Luas area beban diwakili midsurface sehingga berjari-jari $225 \mathrm{~mm}$. Posisi beban dikelompokan menjadi beban di ujung pelat diwakili Titik A, pinggir pelat diwakili Titik B dan C dan di tengah pelat diwakili Titik D. Pengelompokan posisi beban dapat dilihat pada Gambar 2. 


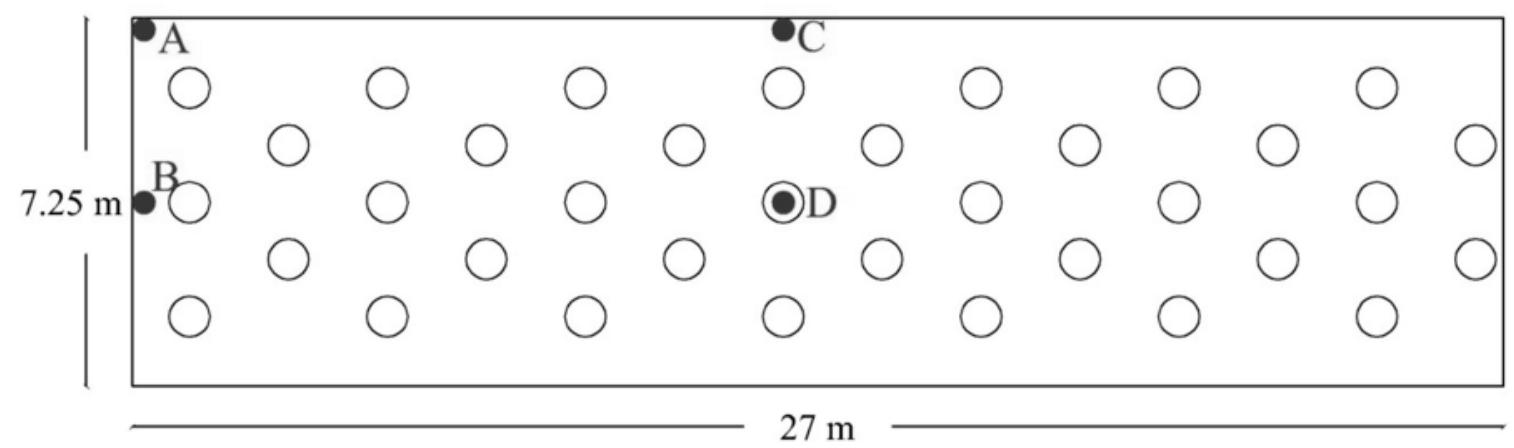

Gambar 2. Perletakan beban model sistem CAM

\section{Sistem CAM}

Data geometri cakar ayam yang digunakan dalam penelitian berdasarkan standart desain cakar ayam dengan referensi desain cakar ayam modifikasi di Pamanukan - Indramayu, Jawa Barat dengan dimensi pelat $27 \mathrm{~m} \mathrm{x}$ $7,25 \mathrm{~m}$, dan variasi jarak cakar pola segitiga sebesar $2,25 \mathrm{~m}, 2,5 \mathrm{~m}$ dan $2,75 \mathrm{~m}$, dimensi tebal perkerasan 0,15 $\mathrm{m}$, tebal pelat baja untuk cakar $1,4 \mathrm{~mm}$, diameter cakar $0,8 \mathrm{~m}$, panjang cakar $1,2 \mathrm{~m}$, tebal koperan $0,15 \mathrm{~m}$, tinggi koperan 0,5 m, properti material berupa beton mutu K350 dan Baja mutu 37. Pemodelan sistem CAM menggunakan beberapa elemen, yaitu elemen shell thin untuk memodelkan pelat, cakar, dan koperan, elemen solid 3D untuk memodelkan tanah di dalam cakar, dan elemen spring untuk memodelkan modulus reaksi subgrade $(k v, k h$, dan $k \tau)$. Desain CAM pada penelitian dapat dilihat Gambar 3

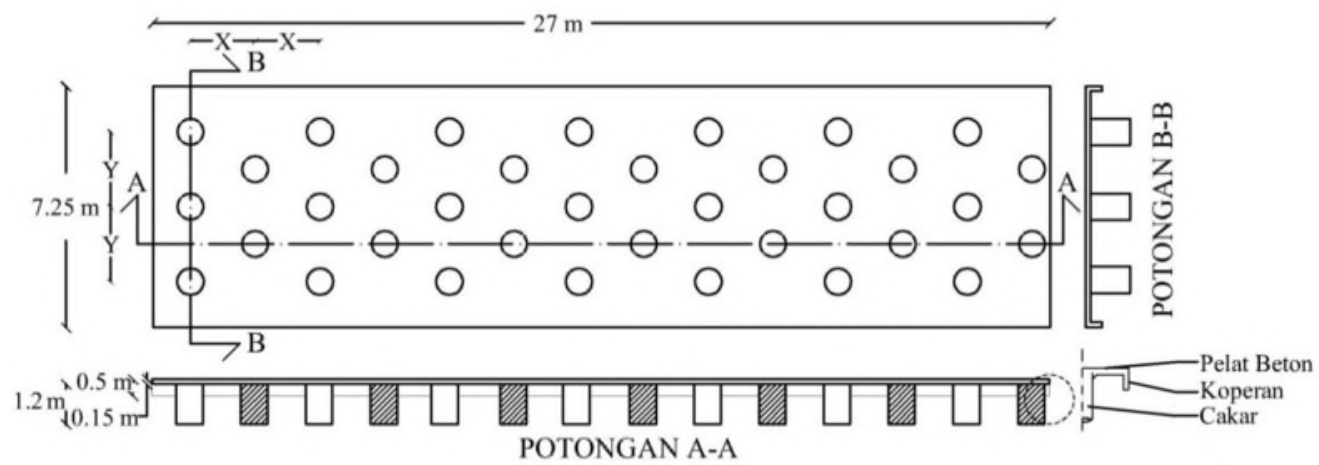

Gambar 3. Desain model sistem CAM

\section{HASIL DAN PEMBAHASAN}

Hasil perancangan model CAM dengan beban ujung, beban pinggir dan beban tengah menghasilkan lendutan yang berbeda menunjukan adanya pengaruh antara variasi posisi beban dan variasi jarak antar cakarnya. Potongan secara memanjang dari lendutan dengan analisis MEH program SAP2000 pada beban ujung, beban pinggir dan beban tengah di tampilkan pada Gambar 4 hingga Gambar 7

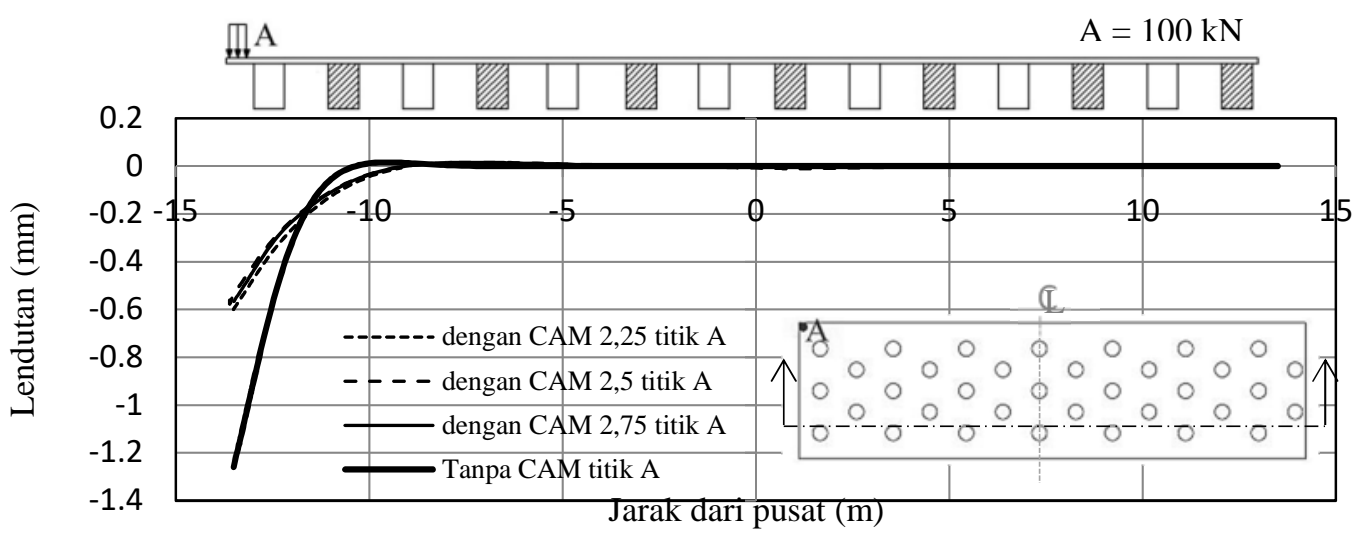

Gambar 4. Hasil lendutan memanjang Titik A pada model CAM 
Gambar 4 menunjukkan bahwa lendutan terbesar yang terjadi yaitu pada posisi beban di ujung pelat pada Titik A dengan jarak antar cakar 2,25 m sebesar 0,6 mm. Nilai lendutan yang terjadi dipengaruhi oleh jarak antar beban terhadap cakar terdekat, semakin jauh letak posisi beban dengan cakar maka semakin besar lendutan yang terjadi. Pengaruh penggunaan cakar dalam menahan lendutan menghasilkan hasil yang lebih kecil dibanding lendutan tanpa CAM sebesar $1,259 \mathrm{~mm}$.

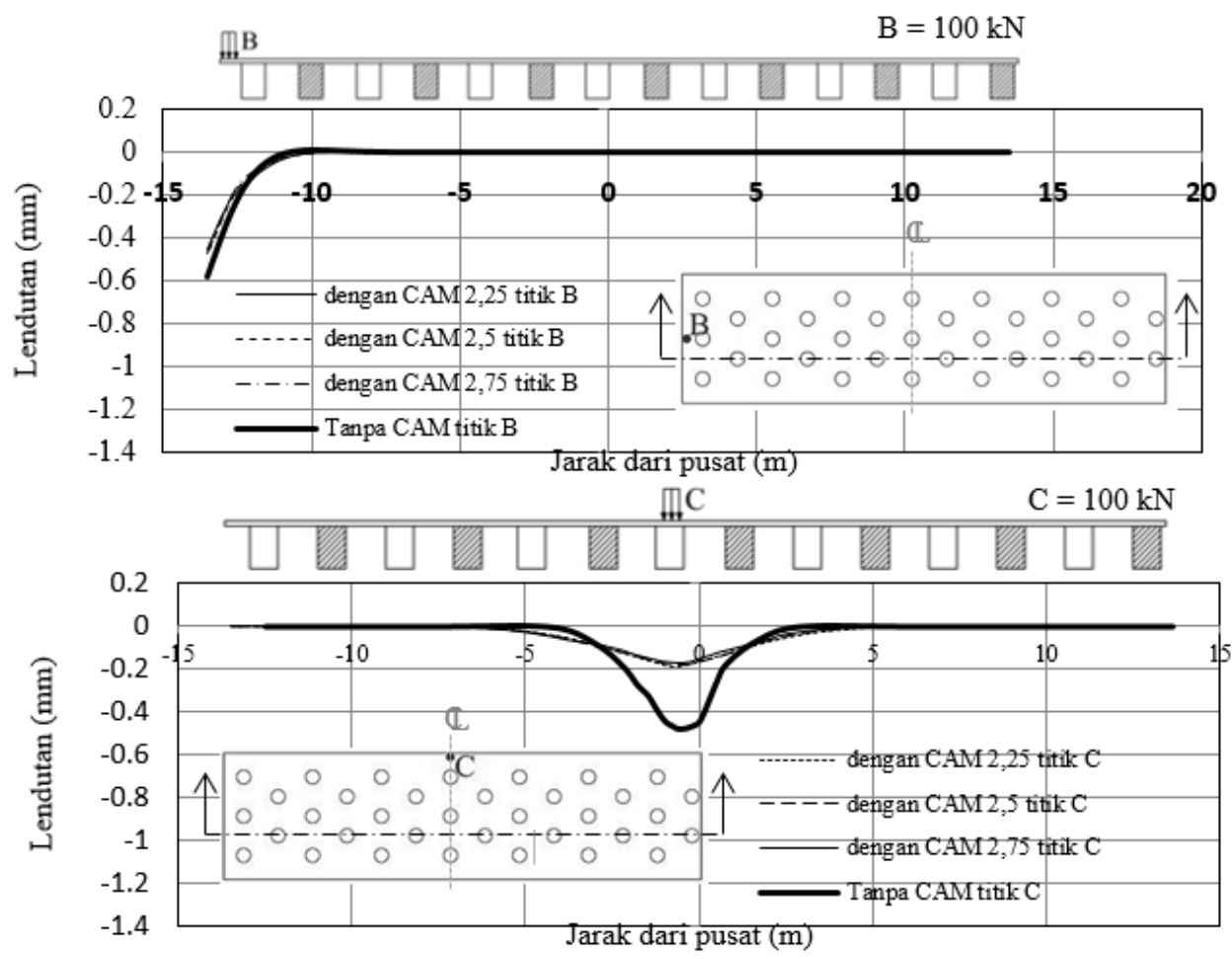

Gambar 5 Hasil lendutan memanjang Titik B dan Titik C pada model CAM

Gambar 5 menunjukkan bahwa lendutan terbesar yang terjadi yaitu pada posisi beban di pinggir pelat Titik B pada jarak antar cakar 2,75 m sebesar 0,475 mm dan di Titik C pada jarak antar cakar 2,25 m sebesar 0,194 mm. Nilai lendutan yang terjadi dipengaruhi oleh jarak antar beban terhadap cakar terdekat, semakin jauh letak posisi beban dengan cakar maka semakin besar lendutan yang terjadi. Pengaruh posisi pinggir pelat secara melintang di Titik B dan memanjang Titik C juga menghasilkan besar lendutan yang berbeda, karena jumlah cakar yang menahan secara memanjang lebih banyak di banding secara melintang sehingga hasil secara memanjang lendutannya lebih kecil. Pengaruh penggunaan cakar dalam menahan lendutan menghasilkan hasil yang lebih kecil dibanding lendutan tanpa CAM sebesar $0,579 \mathrm{~mm}$ pada Titik B dan 0,478 $\mathrm{mm}$ pada Titik C.

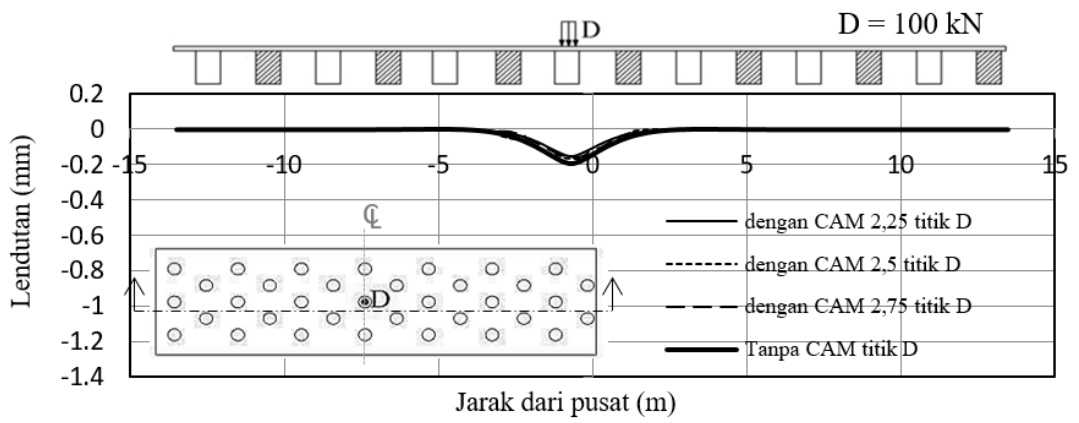

Gambar 6 Hasil lendutan memanjang Titik D pada model CAM

Gambar 6 menunjukkan bahwa lendutan terkecil yang terjadi pada posisi beban di tengah pelat (Titik D) dengan jarak antar cakar 2,25 m yaitu sebesar 0,149 mm. Nilai lendutan yang terjadi dipengaruhi oleh jarak antar beban terhadap cakar terdekat, semakin jauh letak posisi beban dengan cakar maka semakin besar lendutan yang terjadi. Pengaruh penggunaan cakar dalam menahan lendutan menghasilkan hasil yang lebih kecil dibanding lendutan tanpa CAM sebesar 0,196 mm. Hasil nilai lendutan dengan analisis MEH program SAP2000 ditampilkan pada Tabel 1 dibawah ini, dimana nilai terbesarnya ditandai dengan diarsir. 
Tabel 1 Hasil lendutan berdasarkan posisi beban

\begin{tabular}{|c|c|c|c|c|c|c|c|c|}
\hline \multirow{3}{*}{\multicolumn{2}{|c|}{ Posisi Beban }} & \multirow[b]{3}{*}{$\begin{array}{l}\text { Tanpa } \\
\text { CAM }\end{array}$} & \multicolumn{6}{|c|}{ Hasil Lendutan (mm) } \\
\hline & & & \multicolumn{5}{|c|}{ dengan CAM } & \multirow[b]{2}{*}{$\begin{array}{c}\text { Selisih } \\
(\%)\end{array}$} \\
\hline & & & $\begin{array}{c}\text { Jarak } \\
2,25 \mathrm{~m}\end{array}$ & $\begin{array}{c}\text { Jarak } \\
\mathbf{2 , 5 0} \mathrm{m}\end{array}$ & $\begin{array}{c}\text { Jarak } \\
2,75 \text { m }\end{array}$ & Maks & Min & \\
\hline Ujung Pelat & Titik A & $-1,259$ & $-0,600$ & $-0,577$ & $-0,566$ & $-0,600$ & $-0,566$ & 52,34 \\
\hline Pinggir & Titik B & $-0,579$ & $-0,450$ & $-0,448$ & $-0,473$ & $-0,473$ & $-0,450$ & 18,31 \\
\hline Pelat & Titik C & $-0,478$ & $-0,194$ & $-0,182$ & $-0,182$ & $-0,194$ & $-0,182$ & 59,41 \\
\hline $\begin{array}{l}\text { Tengah } \\
\text { Pelat }\end{array}$ & Titik D & $-0,196$ & $-0,149$ & $-0,168$ & $-0,171$ & $-0,171$ & $-0,149$ & 12,76 \\
\hline
\end{tabular}

Tabel 1 menunjukkan bahwa jarak antar cakar mempengaruhi besar kecilnya lendutan, didapat dari hasil bahwa semakin jauh jarak antar cakarnya semakin besar lendutan yang terjadi contohnya ledutan terbesar yang jarak antar cakarnya 2,75 m berada pada Titik B dan Titik D. Lendutan pada Titik A dan Titik C dengan jarak antar cakar 2,25 m menghasilkan nilai terbesar karena posisi beban dan cakar berjauhan. Hal ini karena cakar akan bekerja secara kelompok dalam mereduksi lendutan yang terjadi, namun besarnya perlawanan atau yang dominan adalah cakar yang terdekat dengan posisi beban.

Besar kecilnya lendutan juga bergantung juga pada posisi beban. Lendutan terbesar menggunakan CAM yang berada di pinggir pelat lebih besar dibanding di tengah pelat. Lendutan di pinggir pelat lebih besar karena lendutan di tengah pelat diteruskan ke segala arah area lebih di baik banding di pinggir pelat. Posisi beban yang berada di pinggir secara melintang (Titik B) menunjukan hasil yang lebih besar dibanding sisi piggir secara memanjanng (Titik C), hal ini menunjukkan pengaruh panjang terhadap distribusi ledutan yang terjadi. Perbedaan hasil lendutan di pinggir dan di tengah ini perlu diperhatikan juga untuk perancangan Sistem Cakar Ayam khususnya untuk perkerasan jalan, tempat parkir dan lain sebagainya.

Lendutan yang terjadi pada perkerasan tanpa CAM nilainya lebih besar jika dibandingkan dengan menggunakan CAM, selisih perbandingannya $12,76 \%$ hingga 59,41\% hal ini menunjukan bahwa penggunaan CAM lebih baik dalam mereduksi lendutan. Hasil analisis yang didapatkan menunjukan kesesuaian dengan penelitian sebelumnya pada Romadhoni (2008) yang menyatakan bahwa lendutan terbesar yang berada di pinggir dibanding beban di tengah, kemudian lendutan tanpa CAM lebih besar dibanding tanpa CAM.

\section{KESIMPULAN}

Beberapa hal yang dapat disimpulkan dari hasil penelitian ini adalah sebagai berikut:

1. Lendutan yang terjadi pada perkerasan dengan CAM lebih kecil di banding tanpa CAM selisih perbandingannya $12,31 \%$ hingga $59,41 \%$ pada berbagai posisi beban dan jarak antar cakar.

2. Lendutan terkecil yang terjadi pada posisi beban di tengah pelat (Titik D) dengan jarak antar cakar 2,25 m yaitu sebesar 0,149 $\mathrm{mm}$ dan lendutan terbesar yang terjadi pada posisi beban di pinggir pelat (Titik A) dengan jarak antar cakar 2,25 m yaitu sebesar 0,600 mm.

3. Besarnya lendutan tergantung dari jarak antara posisi beban dengan cakar, semakin kecil jarak antar cakar semakin kecil lendutan.

4. Besarnya lendutan juga dipengaruhi jarak beban terhadap pinggir perkerasan, posisi bebannya berada di pinggir pelat lebih besar dibanding di tengah pelat karena lendutan di tengah pelat diteruskan ke segala arah area lebih di baik banding di pinggir pelat.

\section{REFERENSI}

Abbas, A., 2002, Analysis and Design of Industrial Ground-Floor Slabs using the Finite Element Method, $\mathrm{PhD}$ thesis, Department of Civil \& Environmental Engineering, Imperial college of Science, Technology and Medicine, London.

Depatemen Permukiman dan Prasarana Wilayah, 2002, Panduan Geoteknik 1 Proses Pembentukan dan SifatSifat Tanah Lunak, Bandung.

Firdiansyah, A., 2009, Evaluasi Dimensi Sistem Cakar Ayam Akibat Pengaruh Variasi Beban dan Kondisi Tanah, Tesis, Universitas Gajah Mada, Yogyakarta.

Hardiyatmo, H. C., 2014, Perancangan Sistem Cakar Ayam Modifikasi untuk Perkerasan Jalan Raya Edisi Kedua,Yogyakarta: Gadjah Mada University Press.

Nugraha, W., 2013, Simulasi Perilaku Pelat Beton Sebagai Perkerasan Kaku di Atas Tanah Lunak Dengan Analisis Westergaard Solution, Tugas Akhir, Universitas Sebelas Maret, Surakarta 
Romadhoni, J., 2008, Perilaku Perkerasan Sistem Cakar Ayam dengan Metode Elemen Hingga, Tugas Akhir, JTSDL FT-UGM, Yogyakarta.

Setiawan, B., 2015, Perilaku Sistem Cakar Ayam Modifikasi pada Tanah Ekspansif, Desertasi, Universitas Gajah Mada, Yogyakarta. 